\title{
Hegel y las nuevas \\ \& lógicas del mundo $y$ del Estado. ¿Cómo ser revolucionario hoy?, de Ricardo Espinoza Lolas
}

\author{
Héctor Samour \\ Universidad Centroamericana \\ "José Simeón Cañas"
}

Frente al avance de la globalización neoliberal y la creciente destrucción del planeta, es necesario pensar nuevas lógicas que permitan reconfigurar el Estado y sus instituciones a la altura de los tiempos. Este es el reto principal que aborda el libro de Ricardo Espinoza Lolas, Hegel y las nuevas lógicas del mundo y del Estado ¿cómo se es revolucionario hoy? A partir de una lectura muy heterodoxa de Hegel, Ricardo Espinoza intenta proponer nuevas formas detener la catástrofe humana y ecológica del presente por medio del diseño de nuevas ideas que transformen el mundo: uno verdaderamente operativo, donde el yo deja paso al nosotros, el narcisismo a lo colaborativo y el valor de cambio al valor existencial, proponiendo así, en definitiva, un cambio de civilización que supere el capitalismo actual y sus dinámicas destructivas y deshumanizantes.

Para ello es importante conocer la génesis histórica que nos ha llevado a la situación actual, con el fin de vislumbrar nuevas posibilidades de interpretar y transformar el mundo más allá de lo que impone, como sentido común, la ideología capitalista. Para realizar esta tarea es importante la filosofía de Hegel, pero de un Hegel interpretado de modo afirmativo y revolucionario, de un "Hegel a la altura de los tiempos (no el Hegel de los manuales) y de sus categorías filosóficas" (Espinoza Lolas, 2016, p. 32), tal y como están plasmadas en la Ciencia de la lógica.

Como se sabe, para Hegel la realidad es histórica. Es por Hegel que la historia entra en la filosofía. 
Al ser le compete intrínsecamente la historia. La historicidad no es algo añadido, sino algo fundamental en la constitución de lo real, y por eso la historia queda elevada a rango metafísico en Hegel; la realidad es histórica y no natural. Por esta razón, Espinoza afirma que desde Hegel "no podemos pensar ahistóricamente sea lo que sea, menos a nosotros mismos que somos eminentemente históricos y obviamente nuestra propia sociedad es histórica" (Espinoza Lolas, 2016, p. 32).

Es una tesis que el autor encuentra también en Nietzsche, quien sabía desde el siglo XIX, "que, en el asunto de la historia, se juega el poder, yo diría que el de la ideología" (Espinoza Lolas, 2016, p. 33). $Y$ es que en la ideología, la realidad aparece petrificada bajo la apariencia de neutralidad para todos, con un ropaje de objetividad científica que garantiza cierto conocimiento y eficacia en nuestras actividades cotidianas, ocultando y legitimando la dominación y el sometimiento de los seres humanos, al absolutizar la apariencia y presentar la realidad como algo ya dado por naturaleza, frente a la cual ya nada se puede hacer para cambiarla, dando paso así al "fatalismo de la desesperanza".
La ideología actual opera así desde nuestros más profundos deseos inconscientes, incluso desde nuestra corporalidad, desde la sociedad y hasta desde el territorio virtual en el que nos movemos. Si la realidad es histórica, la ideología la presenta de modo ahistórico, generando discursos y prácticas atemporales, paralizantes y destructores de la vida y de la producción de sentido. Con esto se manifiestan los efectos perversos de la ideología, pues ella nos hace "olvidar el registro de nuestro cuerpo, las huellas físicas de nuestro espíritu, sus fisuras y arrugas, sus pliegues, sus tejidos, su carne, su sangre, sus desechos, sus vértices, su piel, sus tonos" (Espinoza Lolas, 2016, p. 34), ocultando así nuestra identidad y las posibilidades con las que contamos para cambiar la situación actual del mundo.

Este modo de actuar de la ideología se encuentra, según el autor, a lo largo de la historia occidental, en las diversas formas de organización social y política, con la presencia de una ideología inmediata (an sich) que domina y fija todo en el ser dado, que después da paso a otra ideología por negación y superación de la anterior.

Desde la antigua Roma (la ideología de Cayo Octavio Turino) hasta la más reciente modernidad (ideología de Europa con la política francesa, la economía inglesa y la filosofía alemana) se da una ideología que expresa una cierta estructuración institucional de carácter representativo que nos regula, nos organiza, 
nos proyecta, nos define nuestra identidad y, por tanto, en lo que somos, nos movemos y esperamos (Espinoza Lolas, 2016, p. 35).

Se trata de una visión de la historia occidental, inspirada en Hegel, que nos explica nuestra situación actual, en un momento en que la historia del propio Estado en Occidente está crisis y su ideología cuestionada por todas partes. Una crisis del Estado moderno que, según el autor, puede ser interpretada desde la Ciencia de la lógica de Hegel y de sus categorías, las cuales expresan las dimensiones fundamentales de la historicidad del ser humano (del espíritu), y que nos pueden habilitar para diseñar otra ideología, superadora de la ideología capitalista, que promueva otras formas de convivencia ciudadana más solidarias y cooperativas de sociedad, que vayan de la mano con la justicia social y con la justicia económica. En otras palabras, que nos capacite para proponer nuevas lógicas de actuación que posibiliten una transformación revolucionaria del estado actual del mundo.

Lo que es, en la situación que vivimos y lo que nos subjetiva de forma inmediata, no es que solamente sea una construcción técnica sociohistórica, sino que además la podemos cambiar desde adentro en la medida que seamos capaces de ir diseñando ideas que vayan abriendo nuevas lógicas a una lógica trillada $y$ reinante que hoy nos domina. Vivimos en la era del capitalismo globalizado y éste sobrevuela, como la "Estrella de la Muerte" de George Lucas, sobre todo territorio posible del planeta, desde el empírico bien concreto al virtual más innovador, pasando por el inconsciente en su goce más radical, pero incluso en esta era totalitaria se puede y debe ser "revolucionario", y el aporte de Hegel en este sentido es importante.

Para Espinoza Lolas, las dimensiones o momentos de la historicidad están expresadas en los tres momentos que recoge Hegel en su Lógica: la ideología (la doctrina del ser), la técnica (doctrina de la esencia) $y$ el acontecimiento, o toma de decisiones (doctrina del concepto). Si la ideología nos fija en el presente y nos regula y estructura, la técnica perfora el presente desde el pasado vivo y nos dinamiza. El acontecimiento, por el contrario, consistente en la toma de decisiones con vista al futuro, nos abre y nos potencia para transformar la realidad (Espinoza Lolas, 2016, p. 57).

Esto permite comprender la estructura del libro: en el capítulo 1 se abordan las cuestiones del método dialéctico que permiten interpretar el mundo y el nuevo Estado a partir de una renovada lectura de la Ciencia de la lógica de Hegel (Espinoza Lolas, 2016, pp. 65-110). En el capítulo 2 se analiza la manera en que la ideología se estructura en torno al 
elemento lógico de lo inmediato y cómo las distintas ideologías se han expresado históricamente en una idea de Estado, que ya no da más de sí (Espinoza Lolas, 2016, pp. 113-192). En el capítulo 3 se expone la tesis de que la ideología es vehiculada por la técnica misma, esto es, mediante un modo de ser que se ha gestado históricamente, a partir de la negatividad y la mediación, lo que posibilita tanto la construcción de la ideología dominante como también su deconstrucción (Espinoza Lolas, 2016, pp. 193-282). En el capítulo 4 se estudia la Idea como el acontecimiento que posibilita diseñar nuevos Estados, y se evalúan las posibilidades de transformación revolucionaria en el presente (Espinoza Lolas, 2016, pp. 283-371).

La estructura lógica del texto está basada así en el Concepto, cuyo estatuto es el de la esencia del pensar y de la verdad a escala humana, que va de lo más abstracto a lo más concreto, de lo más universal a lo más singular. Una lógica conceptual cuya función es la de cuestionar la ideología y la inmediatez mediante una mediación lógica, un acto reflexivo que permite distanciarnos de la necesidad para entrar en el reino de la libertad (Espinoza Lolas, 2016, p. 107), pero siempre en el marco de la política, en el proyecto de un Estado que debe ser emancipador. Es el camino de la historia, de una historia capaz de reflexionar sobre sí misma y que nos saca del presente de la inmediatez.
Es una interpretación de Hegel que no pretende seguir la interpretación de manual y panlogicista de Hegel; interpretación que no se sostiene en la actualidad (Espinoza Lolas, 2016, p. 354). De hecho, las lecturas especulativas y necesarias de Hegel ya no son reconocidas por los estudios contemporáneos del autor alemán, véanse, por ejemplo, la colección de ensayos críticos sobre Hegel de A. Mac Intyre, o la colección de textos de filósofos sobre el pensamiento de Hegel, de M. Inwood. En el ámbito latinoamericano se pueden destacar las interpretaciones sobre Hegel, de D. Bauer, M. Giusti y de Rubén Drí. La filosofía de Hegel ha vuelto a ocupar un lugar relevante en el marco de la discusión contemporánea - un escenario hasta hace poco dominado por la filosofía kantiana-, especialmente por la vigencia que sus teorías han adquirido principalmente en el terreno de la filosofía práctica. Su particular concepción de la libertad y su noción del "reconocimiento" han sido recuperadas como fuente de inspiración para teorías políticas alternativas. Incluso, la Ciencia de la Lógica considerada hasta hace pocos años por muchos como una deficiente metafísica -entre otras cosas debido a las dificultades de interpretación que suscita- ha despertado el interés de una relectura tanto en el ámbito anglosajón como en el latinoamericano. En este contexto es que se inscribe la interpretación de Ricardo Espinoza del pensamiento de Hegel. 
Se trata de una interpretación que sigue la lectura de Lenin en 1914, e intenta leer a Hegel desde lo esencial de su pensamiento, esto es, desde la Wissenschaft der Logik a partir de lo que acontece hoy (Espinoza Lolas, 2016, pp. 72, 77, 215 y 237), no en la época de Lenin, sino en nuestra época hegemonizada por el capitalismo globalizado. Para el autor, esa lectura leninista de Hegel se volvió fundamental para el movimiento revolucionario de la época, se volvió un Hegel "materialista", no leído solamente desde el carácter inmediato del ser ("La doctrina del ser"), ni tampoco totalmente leído de la mano de la reflexión de la esencia ("La doctrina de la esencia"), sino que leído radicalmente desde el carácter creativo del Concepto ("La doctrina del concepto"), producto de una lectura nietzscheana de Hegel.

Para el autor, en el modelo de ser humano subjetivado en la ideología capitalista no se puede ser un revolucionario, si no se es en cierta forma nietzscheano. Por eso, el Hegel de Espinoza es un Hegel que se vuelve un nietzscheano revolucionario, donde lo Lógico mismo opera como Dionisos, esto es, creando junto a otros nuevas ideas para la sociedad, porque según la Lógica hegeliana así interpretada, sí es posible generar nuevas lógicas y nuevos modelos socioeconómicos emancipadores.

El ser, según la interpretación de Espinoza, funciona naturalizando lo real como la regla que nos mide, nos constituye y nos ideologiza, y con esto el ser humano se aliena en su presente, animalizándose al perder la perspectiva de la apertura y la historicidad de lo real. Según Nietzsche, en esta situación, el ser humano anhela ser animal y estar atado al mero presente de su ser (Espinoza Lolas, 2016, p. 70), esto es lo que ocurre en el capitalismo tardío, que es el que da sentido y presencia al ser humano hoy. El ser humano quiere vivir de forma simple, como "borrego", y por eso se aferra al presente del trabajo y del consumismo, es decir, lo ata en su inmediatez. En términos zubirianos, el ser humano vive aquí no abierto a la realidad, haciéndose cargo de ella, sino en el mero carácter estimúlico de suscitación-respuesta, propio de los animales no humanos.

En este nivel es donde impera la ideología, una ideología que se articula a una con la misma realidad. La ideología de mercado imperante, por ejemplo, es una ideología que se nos impone objetivamente y nos subjetiviza de una forma brutal, y no puede no hacerlo, como lo plantea Espinoza siguiendo a F. Jameson.

Este estado de cosas debe ser superado a través de otro modo de articulación que exprese complejamente la realidad en y por sí misma, en sus múltiples dimensiones, pero que la exprese dinámicamente y que vaya liberando a todo el 
sistema de esa sumisión acrítica a la inmediatez y a lo abstracto; y es el método hegeliano el que nos da las claves para ello y realizar así algún tipo de emancipación (Espinoza Lolas, 2016, p. 77 ss.).

El método hegeliano es un método liberador de la inmediatez empírica en la que está sumido el ser humano, y lo libera para poder diseñar nuevas formas de producciones culturales y para que él mismo tenga un trato libre con él mismo y con los demás. La razón es que el método hegeliano se expresa en redes lógicas, esto es, en lo Lógico y sus mediaciones, que se expresarían en la diversidad de formaciones culturales que el ser humano ha ido produciendo históricamente con el fin de elevarse sobre sí mismo, sobre su carácter empírico e inmediato al que está sujeto con necesidad en el ámbito de la ideología.

Desde la Fenomenología del Espíritu hasta la Ciencia de la lógica, Hegel establece que es la mediación que acontece a través de la cual se da la formación de la subjetividad a nivel individual, social e histórica para posibilitar la humanización del ser humano y de su libertad, y es por eso que en Hegel, el método se constituye como el sistema de redes lógicas de la realidad en su producción histórica, que es lo que define lo Lógico por excelencia. El método es así la expresión sistémica del todo en el todo mismo, en su hacerse.
Para Espinoza, el método hegeliano así entendido, no es un método dialéctico per se, sino que lo dialéctico es un momento del método, no el método mismo. Es un método que pretende liberar a lo real de lo inmediato empírico, al liberarlo de su necesidad, de su carácter sustancial, de su petrificación, a partir de la postulación de su negación y su superación en nuevas formaciones socioculturales, que liberen y realicen más y mejor la realidad humana (el espíritu). Por eso, el método hegeliano es expresión misma de la libertad en los pliegues de lo real. La libertad va de la mano con la negatividad en su proceso metódico. La libertad indica la superación procesual de lo empírico dado sobre sí mismo; de lo inmediato en su propia mediación. Es lo inmediato mismo que se va abriendo y con ello desmontando su atadura inmediatista en el presente.

Esto se aprecia mejor en la dialéctica interna de las configuraciones o de las formas (Die innere Dialetik der Gestaltungen), que Hegel (1955) plantea en sus Lecciones de historia de la filosofía (p. 40). El sucesivo aparecer de la autoconsciencia se explica por la dualidad de forma (Form) y contenido. Siempre que no hay identificación de forma y contenido, porque todavía la forma no es la forma absoluta, hay un principio dialéctico de movimiento, precisamente porque la forma no es expresión plena del contenido, y el 
contenido (la realidad humana) no se satisface con la forma parcial que ha logrado en su devenir. El contenido es siempre más que cualquier forma sociocultural alcanzada en un momento dado, y eso es lo que dinamiza el proceso hacia la consecución de nuevas formas que posibiliten un mayor grado de libertad y humanización.

Por eso, Hegel plantea que el proceso histórico en cuanto tal consiste en el paso de lo en sí racional (das an sich Vernünftige) hacia el ser autoconsciente (Bewusstsein), es decir, algo que ya es en sí racional, y que si no lo fuera no podría racionalizarse nunca, cambia de estado; de ser sustancia a ser sujeto; de un puro ser interno a uno reflejo; de una oscuridad cerrada (Schachte des Geistes), - la ideología, según Espinoza-, a la luz pública (zu Tag ausgebracht); de la esencia intrínseca (Inneres Wesen) a la esencia sabida (Wissen), y todo ello en un sucesivo y permanente despertar. Por eso, la historia para Hegel no trata de lo antiguo cada vez más pasado y aviejado, sino de lo siempre vivo y presente, de lo pasado en cuanto vivo y presente, lo que realmente pervive, y que está continuamente transformándose.

Este momento de negatividad y mediación es el que se expresa en el volumen de la doctrina de la esencia de Hegel, según Espinoza. Si la doctrina hegeliana del ser muestra el nivel del ser en su inmediatez, "el ser es lo inmediato indeterminado" en su primera forma dominante de manifestación (el nivel de la ideología), la doctrina de la esencia nos muestra que ese ser no es eterno y permanente, sino que es manifestación de una actividad esencial que lo ha impulsado a configurarse dinámicamente de una manera determinada y que, por lo tanto, es un ser histórico, atravesado por la mediación.

Por eso, la doctrina de la esencia es la mediación misma del ser inmediato, que a través de la reflexión (Erinnerung) descubre la densidad histórica que sustenta el presente ideológico que nos subjetiva y la sociedad en la que actuamos, y que nos ata en el ser inmediato. La esencia expresa el dinamismo mismo de lo real, su historicidad. En este sentido, la esencia es el ser asumido en su inmediatez, pero en esa medida representa la negación de la esfera del ser en general, que al estar asumido como un ser inmediato ya se le concibe como un ser mediatizado, como un resultado del proceso histórico y, por lo tanto, cargado de negatividad y dinamicidad (Espinoza Lolas, 2016, p. 102).

Desde aquí se da la posibilidad de desideologizarnos y desprendernos de la ideología que nos subjetiva, como principio de liberación del propio sistema. En el nivel de la esencia, se nos descubre que el 
presente es producto del pasado (del trabajo de las generaciones pasadas, diría Marx), donde la esencia es el pasado y opera articulada con el ser que es el presente, como dos planos vinculados ortogonalmente entre sí (Espinoza Lolas, 2016, p. 103). Si en el ámbito del ser inmediato nos movemos en la ideología, sólo mediante las mediaciones va aconteciendo la verdad, pues sólo mediante la conciencia de su historicidad puede el ser humano abrirse a algo distinto y dejar de ser un mecanismo ciego en el marco de una forma sociocultural que considera natural e inmutable, recuperando su identidad (Espinoza Lolas, 2016, p. 207).

La reflexión es lo fundamental de la esencia y es la base para entender el ser en su inmediatez. A través de la reflexión podemos ver lo inmediato en su operar propiamente inmediato, tanto a nivel epistemológico como a nivel ontológico. La reflexión nos vuelve sobre lo que somos, pone al ser humano sobre sí mismo, en su estar inmediato en el mundo, y por ello lleva al ser humano a lo propio de sí. La esencia, dice Hegel en la Ciencia de la lógica, es el "movimiento del devenir y del traspasar que permanece en sí mismo". La esencia pone así la identidad del sujeto, pero no una identidad abstracta, sino una identidad reconstituida de sí misma y en sí misma. Una identidad que nunca está asegurada porque la negatividad la atraviesa continuamente.
Por eso, la identidad siempre es una tarea y un problema, porque el sujeto debe reconstituirse continuamente, pues continuamente debe estar cuestionando (negando) su propia identidad en la que se encuentra en una situación o época determinada. Es una continua reconstitución que sólo puede realizarse desde sí mismo, esto es, desde sus raíces. Es por ello que la memoria constituye aquí un rasgo esencial del sujeto. La memoria es la que nos permite historizarnos y nos vuelve formalmente históricos, posibilitando así la superación de nuestro estado de mera animalidad atada al presente, en un ámbito meramente estimúlico, que sería el dominio de la ideología (Espinoza Lolas, 2016, pp. 212 y 218).

En este carácter de reflexividad está incoado, para Espinoza, el carácter revolucionario de Hegel, y es el que está a la base de Lenin en su lectura de la Ciencia de la lógica de 1914, y que es fundamental en la lectura Zizek y su renovada lectura de Hegel. La doctrina de la esencia es la parte de la Lógica de Hegel donde se conceptualizan no sólo la historia y sus transformaciones, sino de "la propia negatividad en su devenir constructor de la realidad, esto es, en su dialéctica" (Espinoza Lolas, 2016, p. 217).

En la reflexión se juega el carácter revolucionario del ser humano, que es una de las herencias más valiosas 
de la modernidad filosófica europea, según el autor. Solamente la reflexión, en lo esencial, "nos libera de las ataduras necesarias naturalizadas de nuestra subjetivación individual, social e histórica" (Espinoza Lolas, 2016, pp. 103 y 218).

En la doctrina del concepto, el libro fundamental de la Ciencia de la lógica, Hegel plantea el concepto como la articulación entre ser y esencia (Espinoza Lolas, 2016, p. 287), con lo cual quiere expresar que el concepto es la realización efectiva de la realidad en su desarrollo complejo, dando paso así a la concepción de lo real como sistema, historicidad y apertura al futuro, como algo que va aconteciendo afirmativamente entre el reconocimiento entre presente (ser) y pasado (esencia), esto es, entre posición y negación, para dar paso a la negación de la negación (aufheben) por la mediación y la reflexión. "La inmediatez propia del ser es propiamente tal a la luz de las mediaciones de la esencia que la permiten como tal. $Y$ todo este proceso en afirmación es a la vez el concepto" (Espinoza Lolas, 2016, p. 104).

A través de este dinamismo, el concepto va generando la realidad misma, por el que nacen o pueden generarse nuevas ideas, nuevos diseños lógicos de construcción de la realidad más humanos, más libres, que vayan superando dialécticamente la "opacidad, la oscuridad y la barbarie" en todas las zonas de la realidad. En el momento presente, esto abre la posibilidad de "ir limpiándonos del capitalismo que invade todas las zonas de la realidad" (Espinoza Lolas, 2016, p. 105).

Se trata, en toda esta explicación de Espinoza de la doctrina del concepto, de una interpretación nietzscheana de la lógica hegeliana, liberándola de los presupuestos metafísicos que le atribuyen las interpretaciones al uso del autor alemán. "En la voluntad de poder (Wille zur Macht) [...] siempre se esconde interpretativamente la efectuación esencial (Wirklichkeit) con toda su negatividad y, en el fondo, el concepto (Begriff) de Hegel con toda su afirmación" (Espinoza Lolas, 2016, p. 303), o como lo afirma Deleuze, "el sí dionisíaco... es el que sabe decir no; es la pura afirmación, ha vencido el nihilismo y destituido a la negación de cualquier poder autónomo,pero esto porque ha puesto lo negativo al servicio de los poderes de afirmar" (Espinoza Lolas, 2016, p. 303).

Lo Lógico que se muestra en tanto ser-esencia-concepto es primariamente concepto, que es el método por antonomasia. La operatividad misma del concepto con la realidad es lo que Hegel llama Idea. La Idea es la síntesis que lleva en sí misma todas las diferencias en cuanto diferencia. En cuanto la realidad es una unidad con intrínseco dinamismo, es 
por lo que se debe hablar no tanto de diferencia, sino de diferenciación (Unterscheidung) siempre en curso, un momento que se sobrepasa así mismo y que debe captarse en el movimiento del proceso.

Las diferencias constituyen así un todo, una totalidad (Ganze Totalität), precisamente la totalidad que es la Idea (die Totalität der Idee), y esto es lo único concreto y real. Las diferencias son conformaciones diferenciadas, pero son conformaciones totales (ganze Gestalten). La Idea sólo es lo que es en sus formas diferenciadas, y sólo en estas formas aparece el contenido de la Idea. La forma no es una pura forma distinta de un mismo contenido, sino que es el contenido diferenciado y desplegado, y sólo en esa totalidad de formas desplegadas históricamente es lo que da paso a lo que es primordialmente la Idea en la totalidad de lo que tiene que ser y de lo que ha sido.

De esta manera, "La idea expresa lo Lógico mismo en su carácter dinámico de diseño" (Espinoza Lolas, 2016, p. 351), posibilitando así nuevos diseños de lo real, que pueden ser emancipadores. Hegel es así:

\section{El pensador de la libertad, pero deverdad; esto es, desde la libertad mismayen la libertad acontece el dinamismo técnico del bucle que va limpiándose de lo empírico, de toda opacidad, yen ese limpiarse, acontece la ideología, el diseño y toma de decisiones que van dando orientación al bucle (Espinoza Lolas, 2016, p. 353).}

Estos son los presupuestos con los que Ricardo Espinoza ha escrito un libro excepcional, abundante en referencias, ideas y ejemplos. El lector del texto experimenta una especie de paradoja, ya que por un lado se siente atrapado por el discurso pero, por otro lado, abrumado por la corriente de ideas encadenadas de una manera intensa. Es un libro con una estructura formal correcta: introducción, desarrollo y conclusión en cada capítulo y en su conjunto.

La reivindicación de un acontecimiento que dé paso a un cambio radical en la actual situación del mundo nos recuerda la exhortación de Ignacio Ellacuría en 1989; la imperiosa necesidad de un cambio civilizatorio, de una superación radical de la actual civilización del capital para detener la catástrofe humana y ecológica del planeta y avanzar hacia una nueva civilización, una civilización del trabajo o de la pobreza, que genere humanización y libertad no sólo para unos cuantos, sino para toda la humanidad. La reivindicación de los humanos libres, con criterio y deseos propios, en el marco de una nueva política, 
de un nuevo Estado, y yo agregaría, Zizek sino también Nietzsche, Zubiri de una nueva cultura. o Heidegger; y es que lo que hace Espinoza es asimilar creativamente

En resumen, la lectura del a los filósofos que ha trabajado y libro es una tarea enriquecedora con los que ha procesado ideas, para intelectualmente, en el que Espinoza aprender de todos ellos y transtiene buenos referentes, no sólo formarlos en un discurso propio y Félix Duque, Ripalda, Hegel, Lenin o original.

\section{Referencias bibliográficas}

- Espinoza Lolas, R. (2016). Hegel y las nuevas lógicas del mundo y del Estado. Madrid, España: Akal.

- Hegel, G. W. F. (1955). Lecciones de historia de la filosofía (México. Fondo de Cultura Económica. 